\title{
Оригинальный способ ведения семеноводства многоплодных сортов овощных культур
}

С.Д. Соколов, Е.В. Хуторная, А.С. Соколов, А.М. Шантасов, Н.Г. Измухамбетова Семенные растения после проведенного сбора плодов в технической спелости имеют возможность формировать новые семенные плоды, что позволяет проводить повторные сборы и существенно увеличить продуктивность семеноводческих посевов. Оптимальный срок хранения семенных плодов, собранных в технической спелости, позволяет получить семена с высокими посевными качествами. Исследования проводились в 2015-2017 годах в ООО «Наш огород» Камызякского района Астраханской области. На примере сорта кабачка цуккини Юбилейный 450, представлены результаты изучения нового способа ведения семеноводства многоплодных сортов овощных культур, включающего проведение многоразовых сборов семенных плодов не в биологической, а в технической зрелости и последующего хранения, собранных семенных плодов, в течение определенного срока до достижения семенами высоких посевных качеств. В процессе исследований установлено, что оптимальный возраст семенных плодов кабачка для сбора и выделения семян, позволяющий получить наилучшие посевные качества семенного материала, - 50-60 сутки. При этой степени зрелости на 4-6 сутки при проращивании семян в термостате лабораторная всхожесть семян составляла $100 \%$. Для увеличения продуктивности семеноводческих посевов можно проводить сбор семенных плодов в возрасте 20 суток от цветения и сохранять их в течение 20-30 суток до выделения семян. Установлено, что формирование кондиционных семян у снятых с растений плодов проходит быстрее, чем у плодов, находящихся на растении. До достижения высоких посевных кондиций плодам, находящимся на растении, необходимо 50-60 суток, а для плодов, проходящих дозаривание, суммарный период нахождения на растении и их последующего хранения до достижения оптимальных посевных качеств составляет 40-50 суток. На основании проведенных исследований получен патент на изобретение «Способ ведения семеноводства многоплодных сортов овощных и бахчевых культур».

Ключевые слова: кабачок (Cucurbita pepo), семеноводство, многоплодность, техническая зрелость, биологическая зрелость, дозаривание, посевные качества, экономическая эффективность.

системе агротехнических мероприятий, способствующих повышению урожайности и качества продукции, важное место должно быть отведено семеноводству, и, в частности, усовершенствованию научно обоснованных приемов получения семян с высокими посевными качествами [1]. В практике семеноводства кабачка цуккини при одноразовом сборе семенных плодов для выделения семян используются разновозрастные плоды: от момента завязывания до выделения семян проходит у одних плодов до 90 суток, у других 30 и менее - одни плоды успевают перезреть, у других недостаточно времени для формирования выполненных кондици- ка хранения семенных плодов, собранных в технической спелости, позволяет получить семена с высокими посевными качествами [2].

Цель нашей работы: разработка технологии семеноводства кабачка цуккини, способствующей увеличению выхода семян с единицы площади и повышению посевных качеств семенного материала.

Основные задачи исследований:

- Установление сроков проведения сборов семенных плодов и влияния их на посевные качества семенного материала.

- Определение сроков дозаривания семенных плодов разной степени зрелости кабачка цуккини и влияние их на посевные качества семян.

- Определение потенциальной семенной продуктивности семеноводческих посевов многоплодных сортов на примере сорта кабачка цуккини Юбилейный 450 при проведении многоразовых сборов семенных плодов в технической спелости для организации эффективного семеноводства.

Материалы, условия и методика исследований. Исследования проводили в 2015-2017 годах в ООО «Наш огород» Камызякского района Астраханской области. Общая площадь опытного участка 0,5 га, учетной делянки одного повторения каждого варианта опыта $-7 \mathrm{M}^{2}$. Предшественник в опыте - рыбоводный пруд. В III декаде апреля провели плоскорезную обработку почвы (КПГ-250), сплошное боронование (ЗБЗТС-1,0). Посев сорта кабачка Юбилейный 450 - во II декаде мая, пневматической сеялкой СПч по схеме 1,4 × 0,63 м, с последующей раскладкой системы капельного полива. Уход за растениями включал 2-3 междурядных культивации, одно прореживание растений в период массовых всходов, 1-2 прополки вручную. Оросительная норма за сезон составляла 1400-1900 м³/га.

Свои исследования мы проводили на различных бахчевых и овощных 
культурах, в данной статье в качестве объекта исследования был выбран сорт кабачка Юбилейный 450. Основные отличия сорта: открытый одностебельный куст с мягким опушением стебля и черешков листьев. Женский тип цветения с большим количеством бутонов женских цветков, с потенциально очень высокой продуктивностью (на Лиманском государственном сортоиспытательном участке Астраханской области показал урожайность 90 т/га, что в три раза больше, чем у стандартного сорта Грибовский 37). Плод правильной формы, оранжевой окраски, с плотной мякотью и высоким содержанием сухого вещества. Плотные сухие плаценты в семенной камере в недозрелом состоянии способствуют повышению технологических качеств зеленца, но при этом затрудняют отделение семян и ведение семеноводства [3] (рис. 1).

Исследования включали три опыта. В первом опыте, по установлению сроков проведения сборов семенных плодов и влияния их на посевные качества семенного материала, плоды кабачка собирали в возрасте: 15, 20, 30, 40, 50, 60 и 90 суток. Во втором опыте, по определению сроков дозаривания семенных плодов разной степени зрелости кабачка и влияния их на посевные качества семян, были выбраны следующие периоды дозаривания: 10, 20, 30, 40 и 50 суток, которые проводили на плодах различного возраста из первого опыта.

В третьем, производственном, опыте определяли потенциальную семенную продуктивность, при проведении многоразовых сборов семенных плодов в технической спелости, для организации эффективного семеноводства. По использованной схеме опыта сбор плодов кабачка проводили через 25 суток после начала массового цветения женских цветков с интервалом 17-23 суток. За

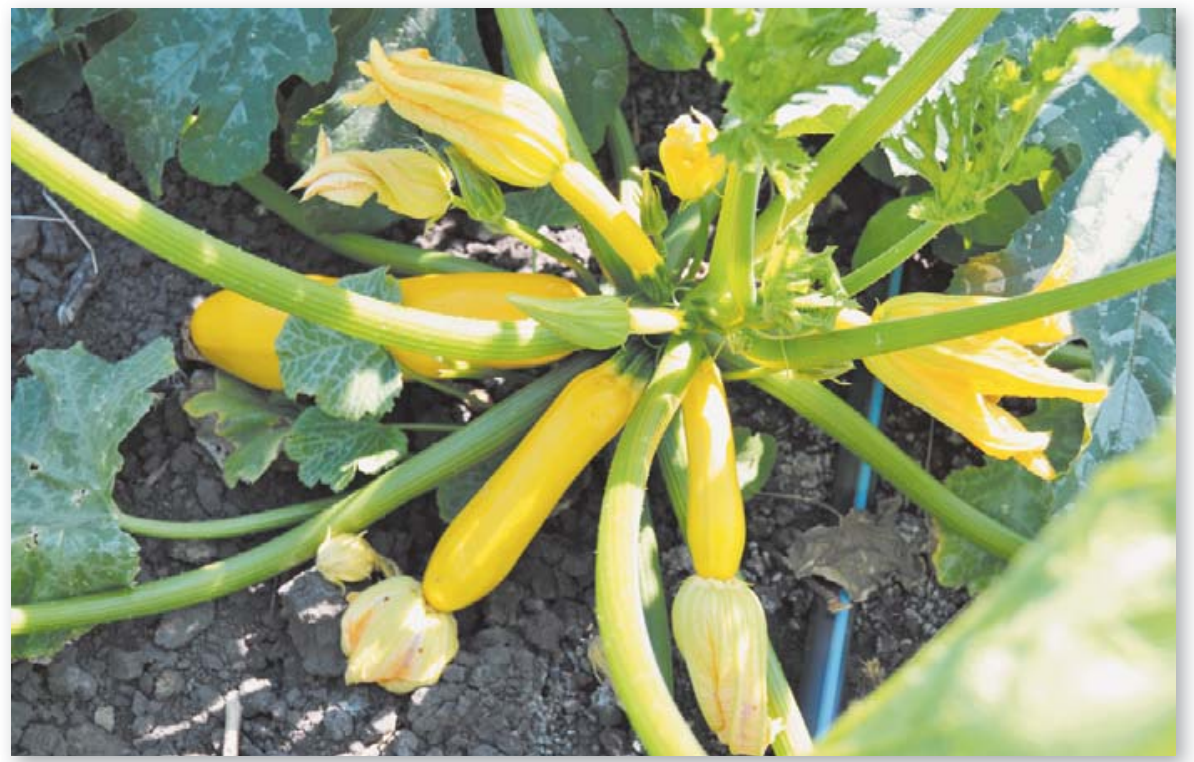

Рис. 1. Многоплодный скороспелый сорт кабачка цуккини Юбилейный 450

период вегетации выполнили 4 сбора семенных плодов. Дозаривание семенных плодов проводили в течение 30 суток в помещении с нерегулируемым температурным режимом.

В течение вегетационного периода проводили фенологические наблюдения: отмечали даты посева, начала всходов и появление массовых всходов, цветения мужских и женских цветков, формирования завязи [4].

Описание морфологических и хозяйственно ценных признаков плода, мякоти и семян. Учитывали среднюю массу, цвет, размер (длина, ширина), твердость коры плода. В опыте 3 учитывали урожайность весовым методом по вариантам опыта при сборе плодов на хранение, и общую урожайность на контроле. Определяли содержание сухого растворимого вещества (СРВ) в мякоти полевым оптическим рефрактометром «Master alfa» фирмы ATAGO в \%. Изучали coстояние плаценты для определения доступности выделения семян (рыхлая, плотная, легко или плохо отделяются семена).

Определяли размер семян (длина, ширина), количество выполненных, пустых и проросших внутри плода семян, массу 1000 шт. семян. Для определения посевных качеств семенного материала после ручной переборки семена закладывали в термостат и проводили определение энергии прорастания и всхожести семян согласно ГОСТ 12038-84 [5].

Расчет экономической эффективности ведения семеноводства новым и традиционным способом проводили по методике определения экономической эффективности использования в сельском хозяйстве результатов научно-исследовательских работ [6].

Результаты исследований. По данным, полученным в первом опыте, 15-суточные плоды кабачка формировали только оболочку семени, в 20-суточных появлялись единичные

\section{Таблица 1. Физические свойства разновозрастных семян сорта кабачка Юбилейный 450 (среднее за 2015-2016 годы)}

\begin{tabular}{|c|c|c|c|c|c|c|c|c|}
\hline \multirow{2}{*}{$\begin{array}{c}\text { Степень } \\
\text { зрелости } \\
\text { семенных } \\
\text { плодов, суток }\end{array}$} & \multicolumn{2}{|c|}{$\begin{array}{c}\text { Количество выполненных } \\
\text { семян в плоде }\end{array}$} & \multirow{2}{*}{$\begin{array}{l}\text { Масса } 1000 \\
\text { шт. семян, г }\end{array}$} & \multirow{2}{*}{$\begin{array}{l}\text { Кол-во семян } \\
\text { в } 1 \text { г, шт. }\end{array}$} & \multicolumn{4}{|c|}{ Фракционный состав, \% } \\
\hline & шт. & $\%$ & & & $\begin{array}{c}\text { крупные } \\
16,0-14,0 \text { мм }\end{array}$ & $\begin{array}{c}\text { мелкие } \\
14,0-12,0 \text { мм }\end{array}$ & $\begin{array}{l}\text { щуплые } \\
\text { семена }\end{array}$ & отход \\
\hline 15 & 0 & 0 & - & - & 0,0 & 0,0 & 25,4 & 74,6 \\
\hline 20 & 12 & 30,0 & 76,1 & 13 & 30,0 & 0,0 & 37,5 & 32,5 \\
\hline 30 & 85 & 48,9 & 112,1 & 9 & 46,6 & 2,3 & 11,7 & 39,4 \\
\hline 40 & 92 & 72,5 & 157,3 & 6 & 65,1 & 7,4 & 16,2 & 11,3 \\
\hline 50 & 119 & 92,5 & 161,4 & 6 & 87,2 & 5,3 & 3,6 & 3,9 \\
\hline 60 & 109 & 91,7 & 164,1 & 6 & 88,0 & 3,7 & 4,2 & 4,1 \\
\hline 90 & 135 & 89,8 & 175,4 & 6 & 82,1 & 7,7 & 5,1 & 5,1 \\
\hline
\end{tabular}


Таблица 2. Посевные свойства семян кабачка Юбилейный 450 различной степени зрелости (среднее 2015-2017 годы)

\begin{tabular}{|c|c|c|c|c|c|c|c|c|c|}
\hline \multirow{2}{*}{$\begin{array}{c}\text { Степень зрелости } \\
\text { семенных плодов, } \\
\text { суток } \\
15\end{array}$} & \multicolumn{2}{|c|}{$\begin{array}{c}\text { Энергия } \\
\text { прорастания, } 3 \\
\text { сут., \% }\end{array}$} & \multicolumn{7}{|c|}{ Лабораторная всхожесть, 10 сут., \% } \\
\hline & 0 & 0 & 0 & 0 & 0 & 0 & 0 & 0 & 0 \\
\hline $15+10$ & 0 & 7 & 7 & 7 & 7 & 7 & 7 & 7 & 7 \\
\hline $15+20$ & 0 & 16 & 32 & 50 & 54 & 66 & 70 & 74 & 80 \\
\hline $15+30$ & 20 & 52 & 56 & 62 & 66 & 70 & 70 & 70 & 70 \\
\hline $15+40$ & 88 & 90 & 90 & 90 & 90 & 90 & 90 & 90 & 90 \\
\hline $15+50$ & 100 & 100 & 100 & 100 & 100 & 100 & 100 & 100 & 100 \\
\hline 20 & 0 & 0 & 0 & 0 & 0 & 0 & 0 & 0 & 0 \\
\hline $20+10$ & 15 & 66 & 66 & 66 & 69 & 69 & 69 & 69 & 69 \\
\hline $20+20$ & 35 & 95 & 100 & 100 & 100 & 100 & 100 & 100 & 100 \\
\hline $20+30$ & 34 & 84 & 86 & 88 & 88 & 90 & 98 & 98 & 98 \\
\hline $20+40$ & 53 & 89 & 100 & 100 & 100 & 100 & 100 & 100 & 100 \\
\hline $20+50$ & 60 & 86 & 96 & 98 & 98 & 98 & 98 & 98 & 98 \\
\hline 30 & 4 & 18 & 28 & 44 & 54 & 62 & 66 & 66 & 66 \\
\hline $30+10$ & 50 & 77 & 80 & 85 & 85 & 85 & 85 & 85 & 85 \\
\hline $30+20$ & 39 & 85 & 95 & 100 & 100 & 100 & 100 & 100 & 100 \\
\hline $30+30$ & 80 & 100 & 100 & 100 & 100 & 100 & 100 & 100 & 100 \\
\hline $30+40$ & 81 & 98 & 100 & 100 & 100 & 100 & 100 & 100 & 100 \\
\hline $30+50$ & 17 & 86 & 91 & 91 & 95 & 95 & 97 & 97 & 97 \\
\hline 40 & 12 & 37 & 42 & 42 & 42 & 42 & 55 & 57 & 57 \\
\hline $40+10$ & 90 & 100 & 100 & 100 & 100 & 100 & 100 & 100 & 100 \\
\hline $40+20$ & 66 & 94 & 100 & 100 & 100 & 100 & 100 & 100 & 100 \\
\hline $40+30$ & 34 & 84 & 100 & 100 & 100 & 100 & 100 & 100 & 100 \\
\hline $40+40$ & 35 & 81 & 94 & 100 & 100 & 100 & 100 & 100 & 100 \\
\hline $40+50$ & 8 & 90 & 92 & 98 & 98 & 98 & 98 & 98 & 98 \\
\hline 50 & 42 & 87 & 96 & 99 & 100 & 100 & 100 & 100 & 100 \\
\hline $50+10$ & 84 & 100 & 100 & 100 & 100 & 100 & 100 & 100 & 100 \\
\hline $50+20$ & 100 & 100 & 100 & 100 & 100 & 100 & 100 & 100 & 100 \\
\hline $50+30$ & 86 & 98 & 100 & 100 & 100 & 100 & 100 & 100 & 100 \\
\hline $50+40$ & 66 & 91 & 95 & 98 & 100 & 100 & 100 & 100 & 100 \\
\hline $50+50$ & 31 & 83 & 89 & 89 & 94 & 95 & 95 & 95 & 95 \\
\hline 60 & 60 & 93 & 100 & 100 & 100 & 100 & 100 & 100 & 100 \\
\hline $60+10$ & 96 & 100 & 100 & 100 & 100 & 100 & 100 & 100 & 100 \\
\hline $60+20$ & 100 & 100 & 100 & 100 & 100 & 100 & 100 & 100 & 100 \\
\hline 90 & 86,6 & 96 & 96 & 100 & 100 & 100 & 100 & 100 & 100 \\
\hline
\end{tabular}

выполненные семена, но они имели очень маленькую массу и были не до конца сформированы.

Жизнеспособные семена в плодах кабачка появились на 30-е сутки после массового цветения. Однако количество выполненных семян в плоде составляло всего $49 \%$. В 40-суточных плодах количество выполненных семян возрастало до $72 \%$, и существенно увеличивалась масса 1000 шт. семян (табл. 1). Но оба эти варианта имели всхожесть ниже 2 класса по посевным качествам - 57$66 \%$, при очень низкой энергии прорастания (табл. 2). точных плодах также отмечены высокие показатели всхожести. Но увеличение возраста негативно отражалось на структурной целостности плодов происходило проникновение воздуха к плаценте, которое провоцировало прорастание семян и разложение мякоти. Было отмечено сильное загнивание отдельных плодов, не позволявшее использовать их для получения семян. Получаемые семена имели темную окраску из-за доступа воздуха и присутствия плесени, неприятный запах, у них существенно снизились посевные качества.

В процессе исследований установлено, что оптимальным возрастом семенных плодов кабачка для сбора и выделения семян, при котором обеспечивались наилучшие посевные качества семенного материала, были 50-60 сутки.

В молодых, 15-20-суточных, плодах кабачка всхожесть семян составила 0\% и, безусловно, необходим был какой-то период для их дозревания. Хранение 15-суточных плодов, даже в течение 10 суток, позволяло получить до 10\% выполненных семян. Дозаривание плодов в течение 20-30 суток обеспечивало формирование в плодах уже близкого к нормальному количества выполненных жизнеспособных семян. Но посевные качества у семян из этих плодов были очень низкими. И только дозаривание 15-суточных плодов в течение 50 суток обеспечивало семенам очень высокую энергию прорастания, уже на второй день проращивания в термостате она была 100\%.

Семена из плодов двадцатисуточного возраста без дозаривания также нежизнеспособны, при дозаривании в течение 10 суток имели энергию прорастания 66\%. Семена из таких плодов после 20 суток хранения имели отличные посевные качества: энергию прорастания 95\% и 100\% всхожесть на четвертые сутки проращивания в термостате. Более продолжительный период дозаривания 30-50 суток также обеспечивал получение семян, соответствующих первому семенному классу. В двадцатисуточных плодах семена достигали стандартной массы 164 г/1000 шт. только после 40-50 суток хранения плодов. Дозаривание этих плодов в течение 20-30 суток давало удовлетворительные показатели по массе семян 145-150 г. Семена, полученные из этих плодов, были выполнены и соответствовали требуемым кондициям.

В варианте с семенами тридцатисуточного возраста также было 
Таблица 3. Продуктивность семеноводческих посевов кабачка сорта Юбилейный 450 при различных технологиях сбора семенных плодов (среднее за 2016-2017 годы)

\begin{tabular}{|l|c|c|c|c|c|c|c|}
\hline \multirow{2}{*}{ Вариант опыта } & \multicolumn{2}{|c|}{ Урожайность семенных плодов по сборам, т/га } & \multicolumn{2}{|c|}{ Урожайность } \\
\cline { 1 - 5 } & I & II & III & IV & общая & семян, кг/га \\
\hline Одноразовый сбор & - & - & - & 14,28 & 14,28 & 195,64 \\
\hline Многоразовый сбор $^{*}$ & 7,97 & 6,35 & 5,60 & 7,31 & 27,23 & 304,98 \\
\hline HCP $_{0,05}$ & & & & & 3,1 & 42,3 \\
\hline
\end{tabular}

достаточно 20 суток для получения высоких семенных кондиций. Оптимальным был вариант с тридцатисуточным хранением семенных плодов: энергия прорастания семян была 100\% и наибольший выход выполненных жизнеспособных семян. Семенам сорокасуточного возраста для достижения высоких посевных качеств достаточно 10 суток дозаривания. Можно отметить, что, как и у тридцатисуточных плодов дозаривание в течение 50 суток приводило к снижению энергии прорастания, хотя по всхожести эти семена соответствовали первому классу.

Дозаривание плодов, находящихся в оптимальной степени зрелости, 50-60 суток, имеющих 100\% всхожесть, требовало непродолжительного хранения в течение 10-20 суток для получения у семян высокой энергии прорастания и некоторого увеличения выхода семян из плодов.

В целом формирование кондиционных семян у снятых с растений плодов проходит быстрее, чем у плодов, находящихся на растении. До достижения высоких посевных кондиций плодам, находящимся на растении, необходимо 50-60 суток, а для плодов, проходящих дозаривание, сум-

марный период нахождения на растении и их последующего хранения до достижения оптимальных посевных качеств составляет 40-50 суток. При этом деструктивные процессы, проходящие в мякоти плодов, идут медленнее.

Таким образом, у кабачка для увеличения продуктивности семенных посевов возможен сбор семенных плодов в возрасте 20 суток от цветения. Для достижения высоких посевных кондиций достаточен срок хранения этих плодов 20-30 суток до выделения семян. Сбор более возрастных плодов также возможен, но может сократить общее количество проведенных сборов и соответственно общую продуктивность семеноводческих посевов.

Кабачок - разновидность тыквы твердокорой. При наступлении биологической спелости кора плода у него становится плотной, иногда деревянистой, что затрудняет процесс выделения семян. Снятые плоды через 15-20 суток после цветения не образуют плотную кору даже после 50-70 суток дозаривания. Эта особенность значительно сокращает время выделения семян, требуя меньших затрат труда.

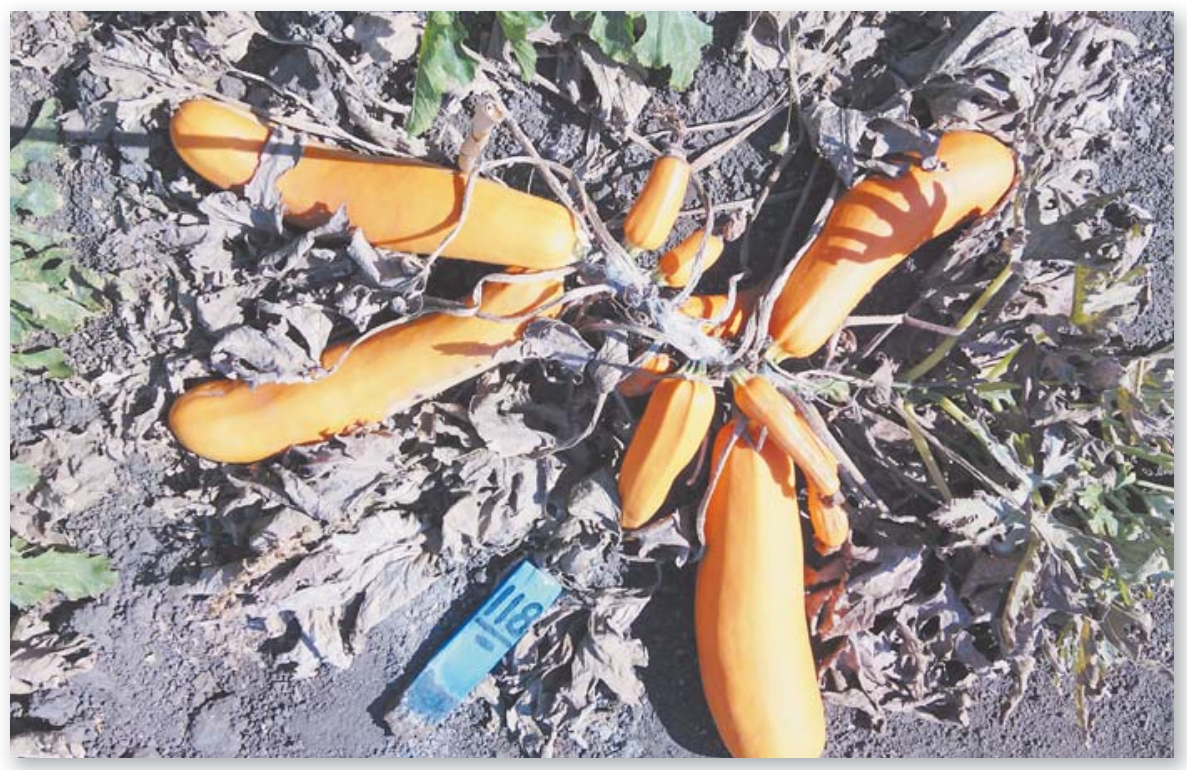

Рис. 2. Отсутствие формирование семенных плодов 3-4 порядка на контрольном варианте без многоразовых сборов
На участке производственного испытания нового способа ведения семеноводства было проведено четыре сбора плодов кабачка цуккини сорта Юбилейный 450. Общая продуктивность растения в любом случае зависит от условий выращивания и режимов питания растения. После образования определенного количества плодов, даже при разных режимах ухода, завязывание новых плодов на растении приостанавливается до формирования уже образовавшихся плодов. Образование новых плодов на растении возобновляется через какой-то, обусловленный внешними условиями, период. Чем больше плодов на растении, тем медленнее они растут, удаление части плодов способствует усилению роста оставшихся, поэтому своевременный сбор плодов у кабачка может иметь большое значение (рис. 2).

При одноразовом сборе общая урожайность семенных плодов была почти в 1,5 раза ниже, чем суммарная урожайность при выполнении нескольких сборов плодов в технической спелости, предназначенных для получения семян (табл. 3).

Выход семян из семенных плодов несколько различался и при однократном сборе был на 22\% выше, чем из семенных плодов, формировавших семена при хранении - 1,37\% и $1,12 \%$ соответственно. Подобная тенденция отмечена и при индивидуальной оценке различных вариантов выделения семян из плодов технической зрелости с выполнением дозаривания и плодов, формировавшихся на растении.

Оценка посевных качеств полученного семенного материала показала высокую всхожесть (96-98\%) у обоих вариантов ведения семеноводства кабачка. Но у семян, проходивших дозаривание в процессе хранения, энергия прорастания была на $20 \%$ выше, чем у семян, полученных при одноразовом сборе.

Многоразовые сборы плодов кабачка для получения семян увеличивают объем затрат на 37\%. Урожай семян при этом способе возрастает на 56\%, что обеспечивает более высокую прибыль от их реализации и, соответственно, на 25\% возрастает рентабельность их производства.

Заключение. Оптимальный возраст семенных плодов для сбора и выделения семян, при котором обеспечиваются наилучшие посевные качества семенного материала у кабачка - 50-60 суток. Для увеличения продуктивности семенных посевов возможен сбор семенных плодов 
в технической спелости, с последующим их хранением до выделения семян в течение определенного срока: у кабачка в возрасте 20 суток от цветения и хранение этих плодов в течение 20-30 суток. Экономическая эффективность производства семян кабачка с проведением последовательных сборов плодов в технической спелости на 25\% выше, чем при одноразовом сборе семенных плодов.

\section{Библиографический список}

1.Соколов С.Д. Организационные проблемы первичного семеноводства бахчевых культур и возможные пути их решения // Материалы научн.- практ. конф. в рамках II фестиваля “Российский арбуз». Астрахань: Нова, 2004. С. 17-21

2.Способ ведения семеноводства многоплодных сортов овощных и бахчевых культур: пат. 2575354 Рос. Федерация: МПК А01C 1/00 А01H 1/04 A01G 7/00 / С.Д. Соколов, А.С. Соколов, А.М. Шантасов, А.Н. Бочарников, С.В. Булыгин, Г.Ф. Соколова; заявитель и патентообладатель С.Д. Соколов, ООО ССП «Мастер семя». № 2014131488/13; заявл. 30.07.2014; опубл. 20.02.2016. Бюл. № 5

3.Соколов А.С., Соколов С.Д., Бочарников А.Н. Шантасов А.М. Перспективные селекционные разработки лаборатории бахчевых культур ГНУ ВНИИОБ // Актуальные и новые направления в селекции и семеноводстве с.- х. культур: матер. Межд. научн.- практ. конф., посвящ. юбилею проф. С.А. Бекузаровой Владикавказ: Горский ГАУ, 2012. С. 203-205.

4.Белик В.Ф. Методика физиологических исследований в овощеводстве и бахчеводстве. М., 1970. 210 с. 5.ГОСТ 12038-84. Семена сельскохозяйственных культур. Методы определения всхожести. М Стандартинформ, 2011. 64 с.

6.Шепеленко Г.И. Экономика, организация и плани рование производства на предприятии: учебное пособие для студентов экономических факультетов и вузов. М.: ИКЦ Март, 2004. 608 с.

\section{Об авторах}

\section{Соколов Сергей Дмитриевич,}

канд. с. - х. наук, научный руководи-

тель. E-mail: sspmaster@mail.ru

Хуторная Елена Владимировна,

главный агроном.

E-mail: sspmaster@mail.ru

Соколов Артем Сергеевич, канд.

с. - х. наук, директор.

E-mail: sspmaster@mail.ru

Шантасов Артур Маратович, канд.

c. - х. наук, агроном-семеновод.

E-mail: sspmaster@mail.ru

\section{Измухамбетова Насыпкан}

Гамединовна, научный сотрудник.

E-mail: sspmaster@mail.ru

Селекционно-семеноводческое предприятие «Мастер семя»

Original method of seed production

runnig for polycarpous varieties of vegetable crops

S.D. Sokolov, PhD, scientific director

E-mail: sspmaster@mail.ru

E.V. Khutornaya, chief agronomist.

E-mail: sspmaster@mail.ru

A.S. Sokolov, $P h D$, director

E-mail: sspmaster@mail.ru

A.M. Shantasov, PhD, seed agronomist.
E-mail: sspmaster@mail.ru

N.G. Izmukhambetova, research fellow.

E-mail: sspmaster@mail.ru

Breeding and seed-production enterprise "Master semya"

Summary. After harvesting fruits at the stage of technical maturity, seed plants afford to cultivate new seed fruits which make it possible to carry out repeated harvesting and significantly increase the productivity of seed crops. The optimal shelf life of seed fruits picked up at the stage of technical ripeness allows to receive seeds with high sowing qualities. The research was conducted in 2015-2017 in "Our garden" LLC of Kamyzyaksky district of Astrakhan region. Via the example of the variety of zucchini marrow Yubileinyi 450, the article shows the results of studying of a new method of seed production of polycarpous varieties of vegetable crops, which includes carrying out of frequent gatherings of seed fruit not in biological ripeness, but at the stage of technical maturity and subsequent storage of collected seed fruits seeds during specified period until receiving by seeds of the high sowing in-spec grades. In the process of research it was found that the optimal age of the seed fruit of zucchini for the gathering and releasing of seeds (which makes it possible to obtain the best sowing qualities of seed material) was 50-60 days. At this degree of maturity, on 4-6 days of seed sprouting in a thermostat, laboratory seed germination was $100 \%$. To increase the productivity of seed crops, it is possible to carry out the collection of seed fruits at the age of 20 days after flowering and store them for 20-30 days before the seeds will be released. It has been established that the development of certified seeds for fruits taken from plants is faster than for fruits on a plant. To obtain high sowing qualities, the seeds in the fruits on the plant need 50-60 days, while for the seeds obtained by the inventive technology the total required period until optimum sowing qualities are achieved (including being on the plant and subsequent storage) is $40-50$ days. On the basis of the conducted research, it was obtained a patent for the invention «Method of conducting seed production of polycarpous varieties of vegetables and cucurbits crops".

Keywords: marrow (Cucurbita pepo), seed breeding, polycarpous crops, technical maturity, biological ripeness, afterripening, sowing features, economical efficiency.

\section{Государство поможет селу}

Минсельхоз России завершил разработку проекта государственной программы комплексного развития сельских территорий. Паспорт документа опубликован на официальном интернет-портале правовой информации.

В результате реализации госпрограммы к 2025 году ожидается увеличение уровня доходов сельского населения по отношению к городскому с 68\% до 75\%, повышение доли благоустроенного жилья с 32,6\% до $50 \%$, а также сохранение численности малых сельских населенных пунктов. Для достижения этих целей планируется направить порядка 1,38 трлн рублей, из них более 1,06 трлн рублей - из федерального бюджета.

Ключевым механизмом госпрограммы станет конкурс региональных проектов, которые будут софинансироваться государством. Такие проекты могут быть представлены коммерческими, некоммерческими и общественными организациями, муниципалитетами, инициативными группами сельских жителей и реализованы по следующим направлениям: социальная инфраструктура и жилье, инженерно-транспортная инфраструктура, культура и спорт, среда проживания, содействие занятости населения, государственные услуги, физическая доступность продовольственных и бытовых товаров, финансовые услуги. Отобранные в регионах заявки будут рассматриваться и ежегодно отбираться для софинансирования Минсельхозом России.

Также в рамках госпрограммы будут осуществляться мероприятия, направленные на улучшение жилищных условий сельского населения. В частности, предусмотрено внедрение льготной сельской ипотеки по ставке не выше $1 \%$ годовых, развитие жилищного строительства и другие меры.

Источник: www.mcx.ru
АДРЕС ДЛЯ ПЕРЕПИСКИ

140153 Московская область, Раменский район, д.Верея. стр.500, В.И. Леунову Сайт: www.potatoveg.ru E-mail: kio@potatoveg.ru тел. 7 (49646) 24-306, моб.+7(910)423-32-29, +7(916)677-23-42, $+7(916) 498-72-26$

Журнал зарегистрирован в Министерстве Российской Федерации по делам печати, телерадиовещания и средств массовых коммуникаций. Свидетельство № 016257 () Картофель и овощи, 2019

Журнал входит в перечень изданий ВАК РФ для публикации трудов аспирантов и соискателей ученых степеней, в международную реферативную базу данных Agris.

Информация об опубликованных статьях поступает в систему Российского индекса научного цитирования (РИнц). Научным статьям присваивается цифровой идентификатор объекта DOI (Digital Object Identifier).

Подписано к печати 8.4.19. Формат 84×108 1/16 Бумага глянцевая мелованная. Печать офсетная. Усл. печ. л. $4,2$.

Заказ № 929 Отпечатано в ГУП РО «Рязанская областная типография» 390023, г.Рязань, ул. Новая, д 69/12. Сайт: www.рязанская-типография.рф E-mail: stolzakazov@mail.ryazan.ru. Телефон: +7 (4912) 44-19-36 